\title{
Tissue distribution and anti-inflammatory activity of corticosteroids incorporated in lipid emulsion
}

\author{
Y. MIZUSHIMA, ${ }^{1}$ T. HAMANO,$^{2}$ AND K. YOKOYAMA ${ }^{2}$ \\ From the ${ }^{1}$ Department of Internal Medicine, St Marianna University, Sugao, Kawasaki, and ${ }^{2}$ Green Cross Co., \\ Miyakojima, Osaka, Japan
}

SUMMARY Dexamethasone palmitate was incorporated into a lipid emulsion (Intralipid, Intralipos) and was injected into rats, and its distribution in the organs and tissues and its antiinflammatory effects were compared with those of free dexamethasone disodium phosphate. The distribution patterns of $\left[{ }^{3} \mathrm{H}\right]$ dexamethasone were markedly different between the 2 preparations in 3 hours after intravenous administration. Dexamethasone palmitate given as a lipid emulsion showed a much higher concentration in the blood, spleen, and inflamed tissues (carrageenan oedema), whereas dexamethasone sodium phosphate had a high concentration in the muscles. The anti-inflammatory activity of both preparations given intravenously was evaluated by using the preformed carrageenan granuloma pouch method. The anti-inflammatory activity of lipid emulsion dexamethasone was 5.6 times as potent as an equivalent amount of free dexamethasone. These results may indicate that corticosteroids which are incorporated in lipid emulsions are taken up by the reticuloendothelial system and some inflammatory cells much more than are free corticosteroids; thus they have a stronger anti-inflammatory activity. The clinical use of lipid emulsion corticosteroids for certain types of diseases is suggested.

The incorporation of a number of drugs in liposomes has been shown to increase their effectiveness and to reduce toxicity. ${ }^{1}$ Liposomes are easily taken up by and retained in phagocytes such as macrophages. By virtue of this property liposome-incorporated corticosteroids inhibit certain types of inflammation in man and animals more intensively than a corresponding dose of free corticosteroids. The problems of liposomal therapy seem to be instability of liposomes and a shortage of experience in clinical use. We incorporated dexamethasone palmitate in a lipid emulsion (Intralipid), which is stable and in widespread use for parenteral nutrition in man. In this paper we report on the tissue distribution pattern of dexamethasone incorporated in a lipid emulsion and its anti-inflammatory activity in the rats.

\section{Materials and methods}

Corticosteroids. Dexamethasone was purchased from Roussel Uclaf Co. Ltd. $\left[6 \cdot 7-{ }^{3} \mathrm{H}(\mathrm{N})\right]$ dexamethasone

Accepted for publication 7 May 1981.

Correspondence to Dr Y. Mizushima, Department of Internal Medicine, St. Marianna University, 2095 Sugao, Takatsu-ku, Kawasaki, 213, Japan.
(Lot $1163-197,5 \mathrm{mCi} / 0.034 \mathrm{mg}$ ) was supplied by New England Nuclear (Boston, Mass, USA).

Synthesis of dexamethasone palmitate and dexamethasone disodium phosphate. (a) Synthesis of $\left[{ }^{3} \mathrm{H}\right]$-labelled dexamethasone palmitate. Dexamethasone $(50 \mu \mathrm{mol})$ and $\left[6 \cdot 7-{ }^{3} \mathrm{H}(\mathrm{N})\right]$ dexamethasone $(0 \cdot 107 \mu \mathrm{mol})$ were dissolved in pyridine $(5 \mathrm{ml})$ at $15^{\circ} \mathrm{C}$. Palmitoyl chloride $(100 \mu \mathrm{mol})$ in ethyl ether $(0.5 \mathrm{ml})$ was added and stirred for 4 hours at $15^{\circ} \mathrm{C}$. The resultant mixture was concentrated in a vacuum at $45^{\circ} \mathrm{C}$. Distilled water $(5 \mathrm{ml})$ and ethanol $(20 \mathrm{ml})$ were added in that order. The mixture was concentrated in a vacuum at $45^{\circ} \mathrm{C}$ to remove water. This procedure was repeated 3 times. The residue was dissolved in a minimum amount of ethanol and was chromatographed on a silica gel column $(2.5 \mathrm{~cm}$ internal diameter, $30 \mathrm{~cm}$ height, kiesel gel 60 , 70-230 meshes, Merck) using a solvent of butyl acetate: benzene ( $1: 1$ by vol.). $\left[{ }^{3} \mathrm{H}\right]$ dexamethasone palmitate fractions checked by thin-layer chromatography were collected and concentrated in a vacuum. The residues were dried over $\mathrm{P}_{2} \mathrm{O}_{5}$ for 24 hours. (b) Synthesis of dexamethasone palmitate. Unlabelled dexamethasone palmitate was synthesised in the same way on a large scale. (c) Synthesis of $\left[{ }^{3} \mathrm{H}\right]$ labelled dexamethasone disodium phosphate and the 
unlabelled one: Both were synthesised by the method of Cutler et al. ${ }^{2}$ with slight modification.

These products were identified by thin-layer chromatography, infrared spectrophotometry, and nuclear magnetic resonance. The radioactivities of $\left[{ }^{3} \mathrm{H}\right]$ dexamethasone palmitate and $\left[{ }^{3} \mathrm{H}\right]$ dexamethasone disodium phosphate were $100 \mu \mathrm{Ci} / \mathrm{mg}$ dexamethasone and $95.3 \mu \mathrm{Ci} / \mathrm{mg}$ dexamethasone, respectively.

Preparation of lipid emulsion. (a) Preparation of a lipid emulsion containing $\left[{ }^{3} \mathrm{H}\right]$ dexamethasone palmitate. A mixture of $9.64 \mathrm{mg}$ of $\left[{ }^{3} \mathrm{H}\right]$-labelled dexamethasone palmitate and $1.436 \mathrm{mg}$ of the unlabelled one (equivalent to $900 \mathrm{mg}$ of dexamethasone) was dissolved in $20 \mathrm{~g}$ of soybean oil containing $2.4 \mathrm{~g}$ of yolk phospholipids. Only the unlabelled one was dissolved for the study of anti-inflammatory assay. The mixture was poured into $175 \mathrm{ml}$ of $2.58 \%$ glycerol aqueous solution while agitating with nitrogen gas. Subsequently the mixture was emulsified with a Manton-Gaulin homogeniser until no particles larger than $1 \mu \mathrm{m}$ in diameter were detectable with the light microscope. The resultant emulsion was put in a $1 \mathrm{ml}$ glass ampoule and sterilised at $121^{\circ} \mathrm{C}$ for $10 \mathrm{~min}$. The particle size of the lipid emulsion was $0.25 \mu \mathrm{m}$ in average diameter and all particles were less than 1 $\mu \mathrm{m}$ in size. The radioactivity of the emulsion was 3 $\mu \mathrm{Ci} / \mathrm{ml}$. The emulsion was stored at $4^{\circ} \mathrm{C}$ until used. (b) Preparation of lipid emulsion. The soybean oil emulsion not containing dexamethasone palmitate was prepared in the same way as described above.

Preparation of dexamethasone disodium phosphate solution. For the study of tissue distribution $\left[{ }^{3} \mathrm{H}\right]-$ labelled dexamethasone disodium phosphate containing some of the unlabelled one was dissolved in saline to a final concentration of $3.95 \mathrm{mg}(3 \mathrm{mg}$ as dexamethasone) $/ 100 \mathrm{ml}$, with a radioactivity of 3 $\mu \mathrm{Ci} / \mathrm{ml}$.

Animal experiments on tissue distribution of dexamethasone. Male rats of Wistar strain weighing 140 to $160 \mathrm{~g}$ were used. Rats were injected with $0 \cdot 1 \mathrm{ml}$ of $1 \%$ solution of lambda carrageenan (Sigma) in saline into the hind paw. $1 \mathrm{ml}$ of either the lipid emulsion containing $\left[{ }^{3} \mathrm{H}\right]$ dexamethasone palmitate or the solution of $\left[{ }^{3} \mathrm{H}\right]$ dexamethasone disodium phosphate was injected via the tail vein $30 \mathrm{~min}$ after the carrageenan injection. The animals were killed with choloroform at a various intervals up to 72 hours after the injection and examined. Blood was obtained by cardiac puncture with a heparinised syringe, and then several organs and paws were removed. The organs and tissues were made soluble with a Soluene-350 (Packard Instrument Co. Inc.) by the usual method, and the radioactivities were measured with a liquid scintillation counter (Packard Instrument $\mathrm{Co}$. Ltd, model B-2450). The concentration of dexamethasone in plasma or organs was expressed in this study by a percentage of a given radioactivity. The weights of whole plasma and of muscles was regarded as 4 and $45 \cdot 5 \%$ of body weight, respectively.

Carrageenan granuloma pouch. Male rats of Wistar strain weighing 110 to $130 \mathrm{~g}$ were used. A $2 \%$ solution of carrageenan (lambda type, Sigma) in saline was sterilised in an autoclave at $110^{\circ} \mathrm{C}$ for 30 min. $6 \mathrm{ml}$ of air had been injected subcutaneously into the back of the animals 1 day before the injection of carrageenan. $4 \mathrm{ml}$ of the carrageenan solution was injected into the air pouch. Five days after the injection of carrageenan animals with pouches of uniform size were selected for further experiments. The test drugs were injected intravenously on days 5,6 , and 7 . The wet weight of granuloma was measured on day 8 .

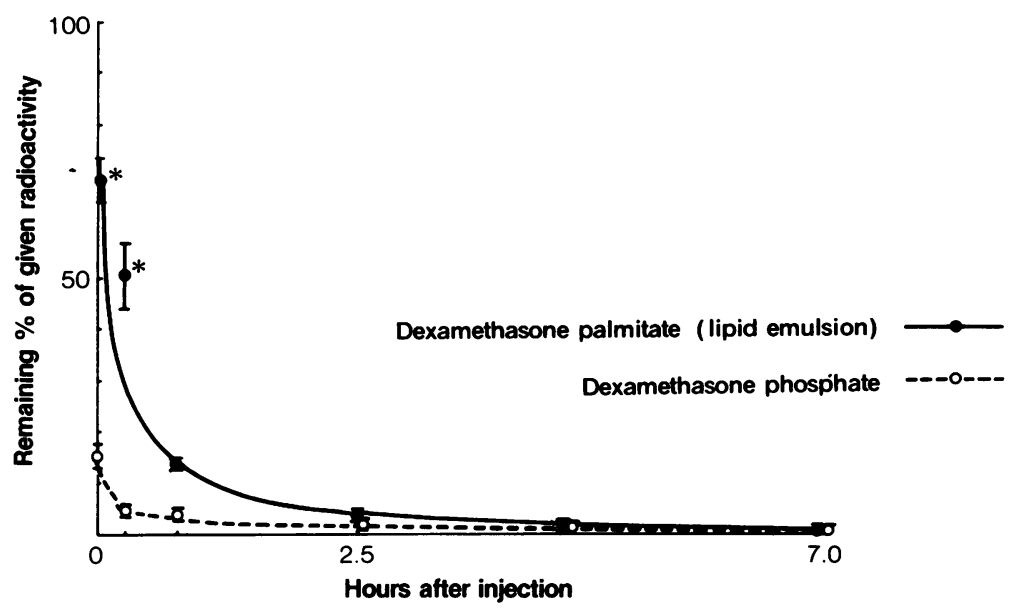

Fig. 1 Plasma concentration of $\left[{ }^{3} \mathrm{H}\right]$ dexamethasone palmitate given as lipid emulsion and $\left[{ }^{3} \mathrm{H}\right]$ dexamethasone phosphate as an aqueous solution in rats. The 2 preparations at the same dose (30 $\mu \mathrm{g}$ as dexamethasone with 3 $\mu C i)$ were injected intravenously and blood was taken several intervals after the injection. Each plot shows the mean value $\pm S E$. Number of animals was 3 or 4 for each determination. ${ }^{*} p<0.05$. 
Table 1 Tissue distribution of $\left[{ }^{3} \mathrm{H}\right]$ dexamethasone palmitate given as a lipid emulsion and $\left[{ }^{3} \mathrm{H}\right]$ dexamethasone phosphate given as an aqueous solution in rats*

\begin{tabular}{|c|c|c|c|c|c|c|c|c|c|}
\hline \multirow[b]{3}{*}{ Organs } & \multirow[b]{3}{*}{ Dexamethasone } & \multicolumn{8}{|c|}{ Percent of given radioactivity (mean $\pm S E$ ) } \\
\hline & & \multicolumn{8}{|c|}{ Hours after the injection of dexamethasone } \\
\hline & & $0^{+}$ & $1 / 4$ & $3 / 4$ & $2 \cdot 5$ & $4 \cdot 5$ & 7 & 24 & 72 \\
\hline \multirow[t]{2}{*}{ Muscle } & palmitate & $8 \cdot 0 \pm 0.4$ & $17 \cdot 3 \pm 1 \cdot 4$ & $19 \cdot 0 \pm 0 \cdot 7$ & $20.5 \pm 0.7$ & $14 \cdot 7 \pm 0.7$ & $7 \cdot 6 \pm 1 \cdot 1$ & $4 \cdot 1 \pm 1 \cdot 8$ & $1 \cdot 7 \pm 0 \cdot 2$ \\
\hline & phosphate & $35 \cdot 5 \pm 5 \cdot 0$ & $28 \cdot 5 \pm 1 \cdot 4$ & $27.3 \pm 0.9$ & $18 \cdot 0 \pm 0 \cdot 3$ & $12 \cdot 7 \pm 3 \cdot 1$ & $10.4 \pm 1.4$ & $6 \cdot 2 \pm 1 \cdot 1$ & $3 \cdot 4 \pm 0 \cdot 5$ \\
\hline \multirow[t]{2}{*}{ Liver } & palmitate & $14 \cdot 1 \pm 2 \cdot 1$ & $21 \cdot 9 \pm 1 \cdot 2$ & $32 \cdot 5 \pm 3 \cdot 4$ & $21 \cdot 2 \pm 2 \cdot 2$ & $14 \cdot 8 \pm 1 \cdot 0$ & $7 \cdot 2 \pm 1 \cdot 4$ & $0.91 \pm 0 \cdot 25$ & $0.40 \pm 0.02$ \\
\hline & phosphate & $21.9 \pm 3.9$ & $36 \cdot 0 \pm 2 \cdot 3$ & $27 \cdot 1 \pm 3 \cdot 0$ & $16 \cdot 1 \pm 2 \cdot 1$ & $10 \cdot 4 \pm 1 \cdot 0$ & $6 \cdot 1 \pm 0.6$ & $1 \cdot 4 \pm 0 \cdot 1$ & $0.73 \pm 0.08$ \\
\hline \multirow[t]{2}{*}{ Kidney } & palmitate & $1.4 \pm 0.3$ & $1 \cdot 9 \pm 0 \cdot 1$ & $1 \cdot 4 \pm 0 \cdot 1$ & $1 \cdot 3 \pm 0 \cdot 1$ & $0.77 \pm 0.02$ & $0.40 \pm 0.02$ & $0.12 \pm 0.01$ & $0.05 \pm 0.01$ \\
\hline & phosphate & $4.5 \pm 0.19$ & $1 \cdot 7 \pm 0 \cdot 14$ & $1.5 \pm 0.14$ & $0.92 \pm 0.05$ & $0.64 \pm 0.03$ & $0.45 \pm 0.08$ & $0.17 \pm 0.02$ & $0.13 \pm 0.03$ \\
\hline \multirow[t]{2}{*}{ Lung } & palmitate & $1 \cdot 2 \pm 0 \cdot 2$ & $1 \cdot 1 \pm 0 \cdot 1$ & $0.70 \pm 0.03$ & $0.46 \pm 0.03$ & $0.27 \pm 0.04$ & $0.19 \pm 0.03$ & $0.07 \pm 0.01$ & $0.02 \pm 0.01$ \\
\hline & phosphate & $1.6 \pm 0.09$ & $0.72 \pm 0.16$ & $0.66 \pm 0.06$ & $0.37 \pm 0.03$ & $0.28 \pm 0.04$ & $0.20 \pm 0.02$ & $0.11 \pm 0.03$ & $0.05 \pm 0.01$ \\
\hline \multirow[t]{2}{*}{ Thymus } & palmitate & $0.11 \pm 0.03$ & $0 \cdot 18 \pm 0.03$ & $0.12 \pm 0.01$ & $0 \cdot 14 \pm 0 \cdot 01$ & $0 \cdot 10 \pm 0.02$ & $0.05 \pm 0.01$ & $0.02 \pm 0.01$ & $0.02 \pm 0.01$ \\
\hline & phosphate & $0 \cdot 17 \pm 0.02$ & $0.13 \pm 0.02$ & $0 \cdot 13 \pm 0.03$ & $0 \cdot 12 \pm 0 \cdot 04$ & $0.08 \pm 0.02$ & $0.07 \pm 0.01$ & $0.03 \pm 0.01$ & $0.01 \pm 0.01$ \\
\hline \multirow[t]{2}{*}{ Hypophysis } & palmitate & 0.006 & 0.006 & 0.006 & 0.001 & 0.001 & - & - & - \\
\hline & phosphate & 0.023 & 0.009 & 0.005 & 0.005 & 0.006 & 0.003 & 0.001 & 0.001 \\
\hline
\end{tabular}

*Number of animals in each group was 3 or 4 . + Immediately after the injection.

\section{Results}

DISTRIBUTION PATTERNS OF LIPID EMULSION DEXAMETHASONE IN THE TISSUES

The plasma concentrations of $\left[{ }^{3} \mathrm{H}\right]$ dexamethasone palmitate, given as incorporated form in a lipid emulsion, and of $\left[{ }^{3} \mathrm{H}\right]$ dexamethasone sodium phosphate, given as an aqueous solution, are shown in Fig. 1. This shows that the plasma concentration of dexamethasone palmitate was higher than that of dexamethasone phosphate a few hours after the intravenous injection. Calculation of the half lives for both drugs from the curves shown in Fig. 1 shows that the $\alpha$ half lives for $\left[{ }^{3} \mathrm{H}\right]$ dexamethasone palmitate and $\left[{ }^{3} \mathrm{H}\right]$ dexamethasone phosphate were 0.32 and 0.14 hours, and the $\beta$ half lives were 2.9 and 2.8 hours, respectively. This indicates that the distribution patterns of 2 preparations differ, but elimination patterns are the same.
The concentrations of $\left[{ }^{3} \mathrm{H}\right]$ dexamethasone palmitate and $\left[{ }^{3} \mathrm{H}\right]$ dexamethasone phosphate in the several organs are shown in Table 1 . In contrast to the concentration in plasma the concentration of $\left[{ }^{3} \mathrm{H}\right]$ dexamethasone palmitate in the muscles was much lower than that of $\left[{ }^{3} \mathrm{H}\right]$ dexamethasone phosphate. This result indicates that dexamethasone phosphate distributes rapidly into such water-rich tissues as muscles after intravenous injection, while dexamethasone palmitate in lipid emulsion is retained in the blood vessels. The concentrations of $\left[{ }^{3} \mathrm{H}\right]$ dexamethasone palmitate in the liver, kidney, and lung were similar to those of $\left[{ }^{3} \mathrm{H}\right]$ dexamethasone phosphate as shown in Table 1 . The concentration of both drugs in the spleen is shown in Fig. 2. As illustrated there, the concentration of $\left[{ }^{3} \mathrm{H}\right]$ dexamethasone palmitate in the spleen was much higher than that of $\left[{ }^{3} \mathrm{H}\right]$ dexamethasone phosphate in 2.5 hours after the injection. This result may be due to the entrapment of

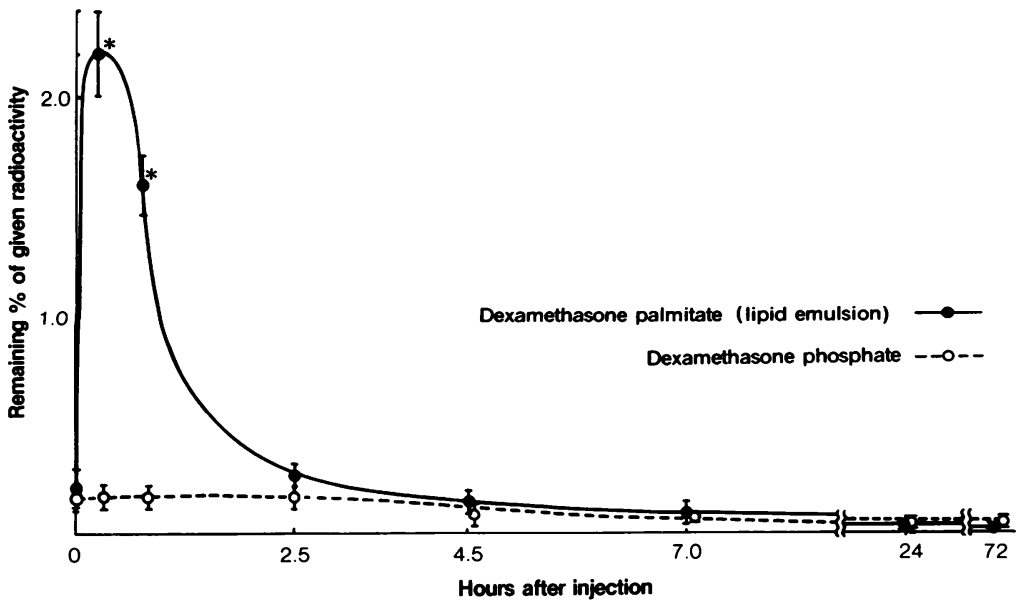

Fig. 2 Accumulation in the spleen of $\left[{ }^{3} \mathrm{H}\right]$ dexamethasone palmitate given as a lipid emulsion and $\left[{ }^{3} \mathrm{H}\right]$

dexamethasone phosphate as an aqueous solution in rats. The 2 preparations at the same dose (30 $\mathrm{g}$ as dexamethasone with 3 $\mu C i)$ were injected intravenously and spleens were taken several intervals after the injection. Each plot shows the mean value $\pm S E$. Number of animals was 3 or 4 for each determination. ${ }^{*} p<0.05$. 
Table 2 Distribution of $\left[{ }^{3} \mathrm{H}\right]$ dexamethasone palmitate given as a lipid emulsion and $\left[{ }^{3} \mathrm{H}\right]$ dexamethasone phosphate given as an aqueous solution into inflamed tissue in rats*

\begin{tabular}{|c|c|c|c|c|c|c|c|c|c|}
\hline \multirow[b]{3}{*}{ Paw } & \multirow[b]{3}{*}{ Dexamethasone } & \multicolumn{8}{|c|}{ Percent of given radioactivity (mean $\pm S E$ ) } \\
\hline & & \multicolumn{8}{|c|}{ Hours after the injection of dexamethasone } \\
\hline & & 0 & $1 / 4$ & $3 / 4$ & $2 \cdot 5$ & $4 \cdot 5$ & 7 & 24 & 72 \\
\hline \multirow[t]{2}{*}{ Inflamed } & palmitate & $0 \cdot 13 \pm 0.01$ & $0.34 \pm 0.06$ & $0 \cdot 38 \pm 0 \cdot 10$ & $0 \cdot 30 \pm 0.03$ & $0.14 \pm 0.01$ & $0 \cdot 12 \pm 0.04$ & $0 \cdot 05 \pm 0 \cdot 003$ & $0.02 \pm 0.003$ \\
\hline & phosphate & $0 \cdot 20 \pm 0 \cdot 01$ & $0 \cdot 20 \pm 0.03$ & $0 \cdot 26 \pm 0 \cdot 05$ & $0 \cdot 14 \pm 0 \cdot 01$ & $0.11 \pm 0.02$ & $0 \cdot 08 \pm 0 \cdot 01$ & $0 \cdot 05 \pm 0 \cdot 01$ & $0.04 \pm 0.003$ \\
\hline \multirow{2}{*}{ Noninflamed } & palmitate & $0 \cdot 10 \pm 0.01$ & $0.13 \pm 0.02$ & $0.17 \pm 0.03$ & $0 \cdot 17 \pm 0 \cdot 001$ & $0 \cdot 11 \pm 0 \cdot 01$ & $0.08 \pm 0.01$ & $0 \cdot 04 \pm 0 \cdot 01$ & $0 \cdot 02 \pm 0.002$ \\
\hline & phosphate & $0.19 \pm 0.03$ & $0 \cdot 18 \pm 0.09$ & $0 \cdot 20 \pm 0.03$ & $0 \cdot 12 \pm 0 \cdot 004$ & $0.09 \pm 0.003$ & $0 \cdot 07 \pm 0 \cdot 004$ & $0.05 \pm 0.01$ & $0.03 \pm 0.004$ \\
\hline \multirow{2}{*}{$\begin{array}{l}\text { Inflamed/ } \\
\text { noninflamed }\end{array}$} & palmitate & $1 \cdot 3$ & $2 \cdot 7$ & $2 \cdot 3$ & $1 \cdot 8$ & $1 \cdot 3$ & $1 \cdot 5$ & $1 \cdot 2$ & $1 \cdot 3$ \\
\hline & phosphate & 1.0 & $1 \cdot 3$ & $1 \cdot 3$ & $1 \cdot 2$ & $1 \cdot 2$ & $1 \cdot 2$ & $1 \cdot 1$ & $1 \cdot 2$ \\
\hline
\end{tabular}

*Number of animals in each group was 3 or 4 .

lipid emulsion dexamethasone in the spleen, which contains many phagocyte cells.

DISTRIBUTION OF LIPID EMULSION

DEXAMETHASONE INTO THE INFLAMED

TISS UES

The distribution patterns of $\left[{ }^{3} \mathrm{H}\right]$ dexamethasone palmitate and $\left[{ }^{3} \mathrm{H}\right]$ dexamethasone phosphate in carrageenan paw oedema are shown in Table 2. Dexamethasone palmitate given as a lipid emulsion accumulated more in the inflamed tissues than dexamethasone phosphate. As described in the methods section above, dexamethasone was injected intravenously $30 \mathrm{~min}$ after the carrageenan injection into the rat paws.

\section{ANTI-INFLAMMATORY ACTIVITY OF LIPID \\ EMULSION DEXAMETHASONE IN \\ CARRAGEENAN GRANULOMA POUCH}

Carrageenan was injected on day 0 to induce a granuloma pouch. Either dexamethasone palmitate in lipid emulsion, dexamethasone sodium phosphate in saline, lipid emulsion lacking dexamethasone, or saline alone was injected intravenously on days 5,6 ,

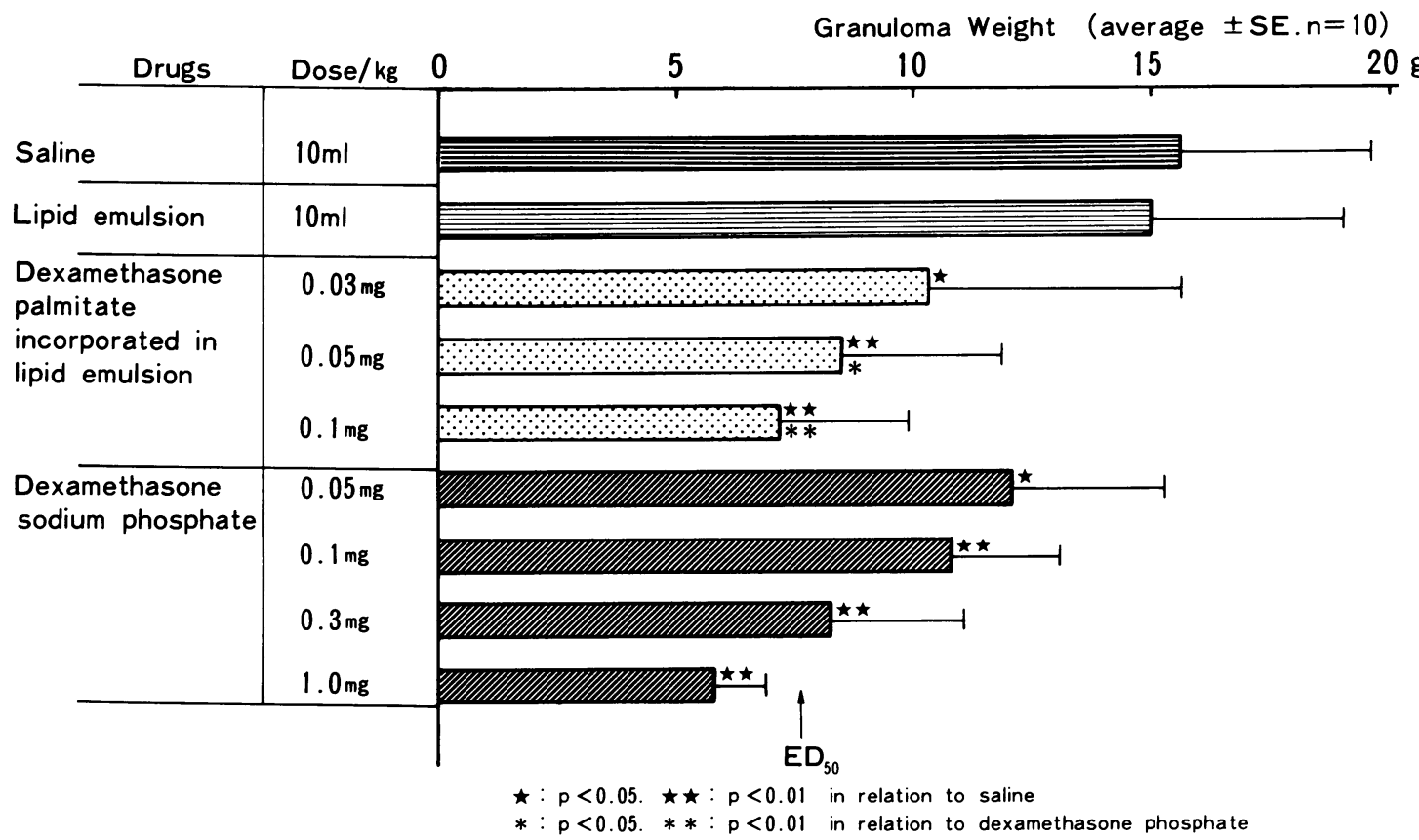

Fig. 3 Anti-inflammatory activity of lipid emulsion-dexamethasone and free dexamethasone on carrageenan granuloma pouches in rats. Carrageenan was injected on day 0 . Either dexamethasone palmitate incorporated in lipid emulsion or dexamethasone phosphate in saline was administered intravenously on days 5, 6, and 7. Dose shown was that as dexamethasone. Granuloma weight was measured on day 8. Number of animals $(n)$ was 10. 
and 7. The weight of granuloma was measured on day 8. The weights of carrageenan granulomas in the treated and untreated groups are shown in Fig. 3. The $E_{50}$ calculated from dose response shown in Fig. 3 was $0.45 \mathrm{mg} / \mathrm{kg}$ for dexamethasone phosphate and $0.08 \mathrm{mg} / \mathrm{kg}$ for dexamethasone palmitate. Therefore the anti-inflammatory activity $\left(\mathrm{ED}_{\mathrm{s0}}\right)$ of dexamethasone palmitate incorporated in the lipid emulsion was 5.6 times as potent as that of dexamethasone phosphate.

\section{Discussion}

In spite of their potency and a variety of favourable pharmacological effects the clinical use of corticosteroids is limited because of their side effects. One idea for reducing the side effects is to localise steroids at the site where they are most needed. Liposomes are good carriers of steroids for this purpose. Liposomes are easily taken up by the reticuloendothelial system (RES) and some inflammatory cells. ${ }^{13}$ By virtue of this property liposom-entrapped steroids show a stronger anti-inflammatory activity than a corresponding dose of free steroids both in man and in animals. Intra-articular injection of liposomal cortisol was more effective than free cortisol in experimentally induced acute arthritis of rabbits. ${ }^{4}$ De Silva and co-workers reported a similar effect of local liposomal cortisol in the treatment of rheumatoid arthritis. $^{5}$

The problems with liposomal treatment may be brought about by instability of liposomes and a shortage of experience in clinical use. Clinical trials of liposomes are restricted to local application. On the other hand a lipid emulsion (Intralipid or Intralipos), which also distributes well into the RES and some inflammatory cells, is very stable and used widely for parenteral nutrition in man. Removal of lipid emulsion particles by the RES ${ }^{6}$ and lipid accumulation in the $\mathrm{RES}^{7}$ have been reported in human beings receiving lipid emulsion.

Accordingly we tried substituting a lipid emulsion for liposome as carrier of corticosteroids to obtain a beneficial distribution. The present study clearly showed that the distribution of corticosteroids into such RES-rich organs as the spleen (Fig. 2) and into inflamed tissues (Table 2) was much greater when corticosteroids were given as a lipid emulsion than an equivalent amount of corticosteroids alone. Therefore a stronger anti-inflammatory activity of corticosteroids incorporated in lipid emulsion is suggested. It was found in this study that the anti-inflammatory activity of lipid emulsion dexamethasone was 5-6 times as potent as the corresponding amount of free dexamethasone. Inhibition of neutrophil chemotaxis has been reported in patients receiving lipid emulsion alone. ${ }^{8}$ However, in the rats given lipid emulsion lacking dexamethasone in our experiment there was no significant effect on their granuloma pouches.

Our study suggests that lipid emulsion corticosteroids are useful in the treatment of several types of diseases. They may include such inflammatory diseases as rheumatoid arthritis, where phagocytic cells in joints have an important role in the pathogenesis, and such diseases as autoimmune haemolytic anaemia and idiopathic thrombocytopenic purpra, in which corticosteroids are effective at least partly by blocking the RES.

\section{References}

${ }^{1}$ Fendler J H, Romero A. Liposomes as drug carriers. Life Sci 1977; 20: $1109-20$.

${ }^{2}$ Cutler F A, Jr, Conbere J P, Lukes R M, et al. Synthesis of cortisone 21-phosphate. J Am Chem Soc 1958; 80: 6300-2.

${ }^{3}$ Shaw I H, Knight C G, Thomas D P P, Phillips N C, Dingle J T. Liposome-incorporated corticosteroids: 1 . The interaction of liposomal cortisol palmitate with inflammatory synovial membrane. Br J Exp Pathol 1979; 60: 142-50.

4 Phillips N C, Thomas D P P, Night C G, Dingle J T. Liposomeincorporated corticosteroids. II. Therapeutic activity in experimental arthritis. Ann Rheum Dis 1979; 38: 553-7.

5 De Silva M, Hazleman B L, Thomas D P P, Wraight P. Liposomes in arthritis: a new approach. Lancet 1979; i: 1320-2.

- Hallberg D. Elimination of exogenous lipids from the bloodstream. Acta Physiol Scand 1965; 65: suppl 254.

7 Koga Y, Swanson V L, Hayes D M. Hepatic 'intravenous fat pigment' in infants and children receiving lipid emulsion.J Pediatr Surg 1975; 10: 641-8.

- Fischer G W, Hunter K W, Wilson S R, Mease A D. Diminished bacterial defences with intralipid. Lancet 1980; ii: 819-20. 